\title{
Language and Interactional Discourse: Deconstrusting the Talk- Generating Machinery in Natural Convresation
}

\author{
Amaechi Uneke Enyi \\ Ebonyi State University, Abakaliki, Nigeria \\ E-mail: mechehunekeenyi@gmail.com
}

Doi:10.7575/aiac.alls.v.6n.4p.171

URL: http://dx.doi.org/10.7575/aiac.alls.v.6n.4p.171
Received: 06/04/2015

Accepted: 11/06/2015

\begin{abstract}
The study entitled. "Language and Interactional Discourse: Deconstructing the Talk - Generating Machinery in Natural Conversation," is an analysis of spontaneous and informal conversation. The study, carried out in the theoretical and methodological tradition of Ethnomethodology, was aimed at explicating how ordinary talk is organized and produced, how people coordinate their talk -in- interaction, how meanings are determined, and the role of talk in the wider social processes. The study followed the basic assumption of conversation analysis which is, that talk is not just a product of two 'speakers - hearers' who attempt to exchange information or convey messages to each other. Rather, participants in conversation are seen to be mutually orienting to, and collaborating in order to achieve orderly and meaningful communication. The analytic objective is therefore to make clear these procedures on which speakers rely to produce utterances and by which they make sense of other speakers' talk. The datum used for this study was a recorded informal conversation between two (and later three) middle- class civil servants who are friends. The recording was done in such a way that the participants were not aware that they were being recorded. The recording was later transcribed in a way that we believe is faithful to the spontaneity and informality of the talk. Our finding showed that conversation has its own features and is an ordered and structured social day by- day event. Specifically, utterances are designed and informed by organized procedures, methods and resources which are tied to the contexts in which they are produced, and which participants are privy to by virtue of their membership of a culture or a natural language community.
\end{abstract}

Keywords: Language, Discourse and Conversation

\section{Introduction}

Talking is something most of us not only do all the time but also enjoy doing. This is because we conduct virtually all our day - day business through the medium of talk-in-interaction (conversation) which could be transactional (for the purpose of getting something done) or interactional (for the purpose of maintaining social relationship). And because we talk all the time we have grown to take it too much for granted. Even in the context of teaching and learning English as a second language, where the basic attention is always given to the four language skills: reading, writing, listening and speaking, the teaching of speaking, which more often than not, implies effective listening, of all the four skills is the most neglected. Bygate (1987:Vii ) aptly captures it thus: "teaching speaking skills is in many ways undervalued". He goes ahead to argue that speaking is a skill which deserves every bit of attention as much as literacy skills.

It is an undisputable fact that most second language users of English who speak reasonably correct and fluent English as a result of their linguistic competence, which is the mastery of the grammar, phonology and the vocabulary of the language, most often than not, fail as conversationalists. It is therefore obvious that conversation involves something more than the manipulation of the linguistic system of a language; it presupposes an ability to engage in a dynamic process of on-going interactive communication (communicative competence) rather than the ability to exhibit a native like control of the language in terms of its phonology, syntax and the lexico-semantic features (linguistic competence). Supporting the above observation, Canale (1983: 68) states that "achievement of communicative competence involves not grammatical but sociolinguistic discourse strategies as well. Bachman (1990) defines conversational competence as:

appropriate use of speech styles according to whom the speaker is addressing and the circumstances under which the act of communication is taking place and this corresponds to pragmatic competence (p.117).

Richards and Sukwiwat (1983: 113) on their part, define conversational competence as: "the speakers knowledge of speech acts which are used in social situations".

Despite the avowed preference of communicative competence over linguistic competence by modern linguistics and the obvious practical value and usefulness of conversational competence and proficiency in enhancing students' ability of listening comprehension and expression; enhancing cultural understanding of the target language in terms of the way of behaviour and norms of social interaction, relatively little attention has been paid to conversation analysis as an independent area of enquiry by scholars until the early 1960s.Before then, much of what has been written about 
conversation is prescriptive in nature and deals with the idea of what makes a good conversation (Burke ,1993). Such studies present sets of social rules that determine which topics are appropriate or the most effective use of language .They do not conceive conversation as a normal everyday human activity or as a structured social event. Rather conversation was conceived as an elite activity governed by the conventions of polite society. This may be attributed to the seeming triviality of conversation which tends to make it less important. Sacks (1973) argues that it is precisely the seeming triviality of talk that makes it important rather than less important. He aptly summaries:

The fine-grained analysis of talk allows for the micro- machinery upon which all else is built to become available to us. Recording natural talk allows very mundane things to take on a great significance precisely because they at first seem obvious. The example of putting a hmm!! into a conversation that is essential to the maintenance of social action (p.12).

What provided the impetus for the development of conversation analysis as an area of study was the work of Garfinkel and Goffman who established the concern for investigating the orderliness of everyday life and this was taken up by Harvey Sacks in his lectures on conversation from the early 1960s (Sacks, 19772). The late 1960s and early 1970s, through the works of Harvey Sacks and his colleagues, Emmanuel Schegloff and Gail jefferson saw the emergence of conversation with the sociological orientation to understand "situations" (the ordinary and extraordinary ways in which people interact with one another in the course of everyday life).Conversation analysis drew from ethnomethodology, an orientation for understanding how order was achieved through interaction, and an empirically based methodology based on micro-analytic studies.

The present study is justified by the above submission and other such perspectives that draw attention to the observed neglect of conversational discourse and social interaction by linguists.

\section{Conversation: Definitions}

The term conversation can be varied and open-ended depending on its conceptualization and the analytical toolkit with which one is looking at it. Conversation, from the framework of Ethnomethodology, assumes a strictly social dimension. Goffman (1976) defines conversation as:

talk occurring when a small number of participants come together and settle into what they perceive to be a few moments cut off from (or carried on the side of) instrumental tasks; a period of idling felt to be an end itself, during which everyone is accorded the right to talk as well as to listen to and without reference to a fixed schedule; everyone is accorded the status of someone whose overall evaluation of the subject- matter at hand... is to be encouraged and treated with respect and no final agreement or synthesis is demanded, differences of opinion to be treated as un-prejudicial to the continuing relationship of the parties (p.264).

Richards and Schmidt (1983) give a graphic description of the term:

One common observation is that conversation has no specific setting, no time or place except for the absence of other speech activity, (in which case it is heard as an interruption), no required rules, other than persons' (though some external roles such as professor/ students may not be shed), no pre-specified agenda and a quorum of simply two or more (p. 133).

Another principal practitioner of Ethnomethodology, Levinson (1983) gives a similar definition.

Conversation may be taken to be that familiar predominant kind of talk in which two or more participants freely alternate in speaking, which generally occurs outside specific institutional settings like religious service law courts, classrooms and the like (p. 34)

All the definitions above are underpinned by Ethno-methodological perspective; scholars from other climes in the field of discourse analysis will favour a technical dimension that will include institutional settings like courtrooms, classrooms and boardrooms (Sinclair and Coulthard, 1975).

Our preference in this study is the treatment of conversation as the talk which is less formal not primarily necessitated by a practical task and involves relatively small number of participants who have equal rights to talk.

\section{Ethnomethodological approach to conversation analysis}

Conversation analysis (CA) is an approach to discourse analysis often associated with a group of scholars known as Ethno-methodologists. Harold Garfinkel and a circle of students and colleagues in California founded Ethnomethodology in the 1960s. His Studies in Ethnomethodology, published originally in 1967 represents the definitive founding text. He adopted a number of innovative research strategies in order to explore the methods actors used in every day interaction to build the sense of social order commonly perceived to exist in interaction. In Ethnomethodological approach, emphasis is always on real data. Working with large amount of naturally-occurring spoken 
language, Ethno-methodologists or conversation analysts attempt to describe everyday linguistic events such as requesting, thanking, inviting, telling anecdotes, e. t. c; to observe regular patterns of behaviour that might indicate adherence to underlying norms or rules of conversation (McCarthy, 1991: 24, McCarty and Carter 1994: 117).

In corollary, conversation analysis is a method for investigating the structure of social interaction between humans. It focuses primarily on 'talk' though it integrates the non-verbal aspects of interaction in its research design. In terms of results, CA studies, yield descriptions of recurrent structures and practices of social interaction. CA elucidates basic aspects of human sociality that resides in talk, and examines the ways in which specific social institutions are invoked in and operate through talk (Richards and Schmidt, 1983). Conversation analysts find out that conversations follow certain rules which can be described. For example, in normal conversation usually only one person speaks at a time; the speakers change, the length of any contribution varies; there are techniques for allowing the other party or parties to speak, neither the content nor the amount of what they say is specified in advance. Silverman (1998: 99) observes that the most basic fact of conversation is the fact that one person saying something to someone else will often contain an expectation of a response. The first speaker's utterance creates a conversational space which the second speaker is expected to fill. It is usually not the case that the first speaker compels the second person to respond or that the nature of the response is determined by the first person. He goes on to illustrate this point by pointing out that it is possible to ignore someone if he/she says "hello" to you, though it is interesting to note that it is not easy as one might think to do so; but if however, over does chose to reject the request contained in an invitation, it is to be taken as an insult. The fact that offence may be taken from a snub lies in the force of the "expectation". Butting into a conversation or speaking out of turn, he further points out is morally regulated in the act of conversation. Conversation analysis investigates how pairs of utterances relate to one another (the study of adjacency pairs), how turn-taking and turn-allocation operate, how conversational openings and closings are effected; how topics are introduced and changed, and how speakers engage in strategic acts of politeness, face- preservation and so on (McCarty 1991: 24). In sum, Ethno-methodologists observe how people orient to the demands of the speech event, and by so doing, enabling us to combine the best features of the old situational approach with communicative approaches stressing the functions that a particular linguistic realizations can perform (McCarty, 1991: 123).

\section{Norms of conversation}

According to Richards and Schmidt (1983),

Conversation is more than just a series of exchange. It consists of exchanges which are initiated and interpreted according to intuitively understood and socially acquired rules and norms of conversational cooperation which can, in turn, be manipulated to create a wide range of meaning beyond the level expressed directly by the utterances in the conversation itself (p. 122).

This is clearly captured by the general principles of conversational behaviour proposed by Grice (1975) as central for successful communication. These norms are called 'maxims' and are based on the idea that contributors to a conversation are rational beings; that is, they obey a general principles of rationality known as cooperative principle.

This principle is formulated by Grice as follows:

Make your conversational contribution such as is required, at the state at which it occurs by the accepted purpose or direction of the talk exchange in which you are engaged.

In order to fulfill the cooperative principles, the speaker must follow the nine maxims of conversation which have been articulated and grouped into four categories thus:

1. Maximum of quality (informativeness)

i. $\quad$ Make your contribution as informative as required.

ii. Do not make your contribution more informative than required.

2. Maxim of quality (truthfulness)

i. Try to make your contribution one that is true.

ii. Do not say what you believe to be false.

iii. Do not say that for which you lack adequate evidence.

3. Maxim of relation (Relevance)

i. Be relevant.

4. Maxim of manner (be perspicuous)

i. Avoid obscurity of expression

ii. Avoid ambiguity

iii. Be brief

iv. Be orderly.

Conversational implicatures are pragmatic inferences, which are not tied to the particular words and phrases in an utterance but arise instead from contextual features another understanding the conventions are observed in conversation. They are inferences based on the normal assumption that the conversational maximum is being followed. 


\section{Structure of conversation}

Conversation has a definite structure and reflects the procedures that govern face-face encounters. This is seen in opening and closings, topic management, turn-taking mechanisms, and repairs or conversational strategies.

\section{Openings and closing}

Conversations do not simply begin and end. There are many ways of starting a conversation and most of them are fairly ritualized. Wardhaugh, (1985:118) gives the following ways: adjacency Paris of greetings and introductions, questions for finding some common grounds, comments on the actual circumstances of the meeting itself, comments on the weather, general complaints, pseudo-apologies e.g. excuse me: and so on. Openings allow for further talk once the other persons attention has been obtained.

Closing, like opening is also a cooperative activity. According to Bardovi-Harlig etal (1991):

Closing is a matter of politeness and thus we need to use some essential components of "felicitous closings;" i.e. the terminal exchange, the preclosing and the shut down while considering the situational variables such as the setting and the relationship of the participants as well as cultural differences (p. 6).

Pre-closing signals include: Ok then, All right, so... well, I suppose, Erm... I'm afraid, I've got to go now, I'll let you get back to your writing, it is been nice talking to you and so on.

\section{Topic management}

The way speakers in a conversation select the topics for discussion and the strategies they use in nominating, developing them constitute an important dimension of conversation organization (Richards and Schmidt, 1983). For example, for a conversation to be coherent, speakers must handle topics delicately by respecting the norms concerning the choice of topic Richards (1990:70) uses the tern topicalizing behaviour to mean bringing up topics, responding to other people's topics, mentioning something, avoiding the mention of something, carrying the discussion one step further and so on. Coulthard, (1975) observes:

we experience, see, hear, about events all the time, some are tellable, some aren't and of those that are tellable, some are tellable to everyone, some have restricted audience, some must be told immediately, some can wait and still retain their interest (p. 79).

In the perspective of Richards (1990), Participants select a topic as first topic through a process of negotiation.

\section{Turn- taking mechanism}

The turn- taking system is basic to the management of the collaborative process of a conversation. There are a variety of strategies or devices used in turn- taking. Wardhaugh (1985) lists the following: using interjections to signal a request for a turn, (eg: Mn-hum, yeah) and rising intonation, accepting a turn offered by another speaker by providing the second pair part of an adjacency pair, completing or adding to something said by the previous speaker, and so on. In order to hold a turn, speakers use devices indicating they are making a series of remarks: first of all, or to begin with, followed by then, after that, next, etc. Expressions such as: another thing, connectors like: so, because and however promote continuity.

\section{Repairs in conversation}

Conversation is reciprocal. Cook (1990) states that a speaker can monitor reception and adjust to it, or to put it differently, the listener can influence the development of what is being said. The term 'repairs' according to Schegloff et al (1977: 147) refers to efforts by both parties in a conversation to correct communication trouble- spots such as not knowing a particular word, or misunderstanding the other speaker. Other terms like conversational strategies (Dornyei and Thurrel, 1994) and conversation adjustments (Bygate, 1987) have been used synonymously with the term. Repairs can be seen as a kind of feedback within turns and may be initiated by either the speaker, (self-repairs) or the hearer (other repairs), checkers, such as Ok. are you with me? , got it, e t c, may be used to find out whether the audience is still attentive or whether there is any problem in following the talk; expressions like: huh? What? And I'm sorry, can be used to signal the need for repair. Facial expressions and other kinesics signals also perform the same function. Another technique that is often used is echoing; the hearer repeats a word or phrase which is not understood, thereby asking for clarification, and the conversational partner explains it or replaces it with an easier item (Richards and Schmidt, 1983:148).

\section{Adjacency pairs}

Adjacency pairs are the basic structural units in conversation (Coulthard, 1985:70). They refer to utterances produced by two successive speakers in which the second utterance can be identified as related to the first as an expected followup. For some first parts, the second pair part is reciprocal (Greeting/Greeting), for some, there is only one appropriate second, question/ Answer); for some others, there are a variety of options, (complaints/ Apology/ justification) which can be explained by the preferred and dispreferred responses (Levinson 1983: 307). 


\section{Analysis and discussion}

This conversation (see appendix) shows the exchanges between three participants. The first two women are intimates and neighbours and the third woman a passer-by and also their friend. The close relationship between these participants results in a very informal style of conversation. Consequently, the talk is basically interactional though spiced with the transactional elements of exchange of information.

The conversation's opening device is a question which interactionally functions, not as a question that elicits an answer, but as an attention-catching device or as a summon which serves to secure a co- participant for a conversation. Mama Udoka (turn 1.) throws the question "what is this country turning into eh? It also serves as a device for finding a common ground for a conversation. Such openings as this allow for further talk once the attention of the other participant (s) has been obtained. Mama Nkechi's response in (turn 2) "what is it, Mama Udoka," and "Oh! Is it the bombings and killing of innocent citizens of the country by Boko Haram?" (turn 6), functions to signal to Mama Udoka that she was not only following the talk but also understood the "topic" of the talk . Therefore, part of the structure of conversational opening has to do with the positioning of topics within the conversation (Schegloff and Sacks 1973). According to Wardhaugh (1985:119), what is crucial in opening a conversation is "being able to access accurately the context in which it is to take place and some of the salient features of the other person, and to have command of the derives that will be necessary to keep the conversation going, once you overcome the initial difficulties". As intimate friends and neighbours, Mama Udoka knows that Mama Nkechi will certainly respond to her question in some way or specifically, by asking for further information or clarification. Follow-up questions interactively led Mama Nkechi to make the first mention of the supposed topic of the conversation and that provides her with a discourse frame to not only to develop and maintain the topic which tells a tellable event -the bomb blast at Mandala, on Christmas day but also to negotiate a sub-topic which adds that the only son of Mazi Nnachi died in the bomb blast. "Yes now, this thing is getting out of hand. Do you know the latest? We heard that the bombing which took place in Madala in Niger state on Christmas day killed the only surviving son of Late Mazi Nnachi. (Turn8.).

Richards (1990) explains that participants negotiate and select topics for conversation through a process of 'topicalizing behaviour' by which he means the ways participants bring up topics, respond to other people's topics ,mention some things and avoid the mention of some other things; carrying the discussion one step further, and so on. Structurally, this conversation is initiated, developed and sustained by the use questions which naturally come up from the context of the talk. Mama Udoka initiates the talk ( turn 1) by posing a question, Mama Nkechi, (in turn 2) instead of giving a direct answer, asks a question in return. Her question is interpreted as an answer on the assumption that she conforms to the maxim of relevance. Having established a common ground, through the cooperative responses of her conversational partner, Mama Nkechi, who nominates the topic, Mama Nkechi's further question (in turn 6), "Oh! Is it the bombings and killing of innocent citizens of the country by the Boko Haram , serves as an elaborating move which helps to develop and sustain the topic. Mama Nkechi's expression in( turn 10), "Don't say that again ", is a monitoring device that conveys mama Nkechi's surprise at the information that Mama Udoka is giving, as well as to show that she is monitoring Mama Udoka's talk. Such utterances are interactively very important as they function to encourage the speaker to talk more or to expatiate on the topic. This proves to be a very strategic device for topic elaboration and expansion as it affords Mama Udoka the opportunity to spice up the topic with some pieces of additional information that the man killed in the Mandala bombing was the only surviving son of Late Mazi Nnachi; that his mother was sick, and her sickness being as a result of injuries she inflicted on herself during her husband's burial recently.

Turn 18 shows a strategy that speakers who are non- participants in an ongoing talk can employ in order to join in a conversation. The formal feature of the turn shows that it begins with "sorry" which functions to mitigate negative face and followed by what can be interactively described as a passage to, or an entry into a conversation. Mama Ibe, here used this device to mitigate the force of her interruption and to orientate to the ongoing topic Boko Haram: "sorry to interrupt your conversation, I heard you say Boko Haram" (turn 18).

The intimacy between the co-interractants and the sheer informality of the conversation is underscored by the use of rhetorical devices which are deployed as pre-expansion sequences which occur between the first pair parts of a question-answer adjacency Pairs and the second pair parts.

\section{Mama Udoka: How can you be asking that kind of question?}

\section{Are you from the moon?}

Other informality features found in the conversation is the use of "code-switching" and "code-mixing" of English and Igbo languages especially in form of discourse markers and hedges, as well as other features of Nigerianisms.

14. Mama Nkechi :" Ewooh!" and now her only son.

15. "Chei!" Are you sure someone is not behind all this.

22. Mama Udoka : Mama Nkechi did you hear that? "Chineke onye ebere".

24. Mama Nkechi : "Ewooh”! What did you just say?

27. Mama Ibe : "You'll not even see the leg" to come out from the place.

Another prominent device used in this conversation is "pre -telling (pre-announcements)" (Sacks, 1973), which is a device that indicates that the speaker has something to tell, but gives no additional information about the telling or used to give the recipient more information about what they will involve. Strictly speaking, pre- tellings are formulaic acts 
that function to alert the recipient that what is to follow is a telling of some items of news. In turn 8 , Mama Udoka pretells: "Do you know the latest", and in( turn 11) she says:" you mean you've the not heard it". These serve to enable the recipient to recognized the telling, as news in terms of its imports.

The closing of the conversation is achieved through the strategy- "announcing closure" which is a device that usually invokes some external circumstances which warrant the ending of the current conversation. According to Liddicoat (2007: 259)

one obvious way in which a conversation may move to closure is if one of the participants announces closure as a relevant next action in some point in the conversation. Such announcements of closure usually invoke external circumstances which warrant ending the current conversation...

In turn 28, Passer-by announces a closure to the conversation citing an external circumstance which affects her ability to continue with the conversation.

28. Passer - by: 1 just managed to come out now to rush to my place of work to sign my name in the attendance register...

She disengages from the conversation by uttering the first pair part of a "terminal sequence":

29. Passer - by: Let me run along, bye.

This proposal to end the conversation was collaborated by both Mama Udoka and Mama Nkechi who uttered the second pair part of the terminal sequence:

30. Mama udoka and Mama Nkechi : Bye! Bye.

The second and final part of the closure was proposed by Mama Udoka who announced closure by citing an external circumstance that tends to cut short her participation in the conversation:

31. Mama Udoka : If not that I am already late for work...

Mama Nkechi in turn 33 finally closed the conversation by uttering a pre-closing token: 'I am going" which was followed by the first pair part of a terminal sequence: Bye!- (turn 34). Mama Udoka accepts the closing by completing the second pair part: "Bye! Bye!"

The exchange of good Byes in a conversation interactively constitutes adjacency pairs as the production of one goodbye makes the production of another, a relevant next action for a co- conversationalist. The production of the first, proposes a closing, while the second, accepts the proposal. The use of such adjacency pairs to close a conversation means that closing is achieved collaboratively by the parties to the conversation as the failure to do this would create a negative interactional effect.

The analysis in this study, which is based on certain features within the overall structural organisation of the conversation, has revealed among other things that the conversation consists of organised set of practices that are mutually carried out by participants. The analysis of the various structural components of the conversation which include; the opening and closing, topic nomination and development, sequencing of actions and the overall taking and operation of turns has shown that conversation is not just two or more persons who are engaged in a form of linguistic communication rather, conversational exchanges involve organised set of practices which participants carry out in order to take and construct turns, build sequences of actions, repair trouble spots, select the right words to construct a turn and ultimately to make meaning of is being said. This organised set of practices is what Sacks (1972) used the metaphor of "machines or machinery" (which has also been adopted in this study) to describe. According to Sacks (1975:169), “... interactions are being spawned out by machinery, the machinery being what we are trying to find; where, in order to find it, we have got to get a whole bunch of its products". Sidwell , (2010) agrees with Sacks when he observes:

...there is an organised set of practices involved in first, getting the talk started, secondly, constructing a turn, another such organised set of practices involved in producing sequences of action another set of practices involved the initiation and execution of repair and so on (p:3).

We have seen also that utterances come in particular places within the overall structural organisation of an occasion. And for a given occasion, there are certain places within it, at which point, particular actions are relevant to be performed. Greetings, for instance are properly done at the beginning and when it is done outside its proper place in a conversation, it is typically marked as such by the use of displacement markers.

Our analysis has also shown that participants design their talk in such a way as to make it appropriate and relevant for the other person. Sacks, Schegloff, Jefferson (1974:727) refer to this practice as "recipient design" and define it as "The multitude of respect in which the talk by a party in a conversation is constructed or designed in ways which display an orientation and sensitivity to the particular other(s)". Recipient design encompasses a whole range of practices in talk which include such practices as a speaker increasing the volume of his talk to address a recipient that is farther off and 
the nuances of word selection which reflect what the speaker assumes the recipient already knows. So with an expression like "that" in, that was fun, the speaker presumes that the recipient will know what he means,

The data also revealed that the endings of conversations are also achieved through a set of organised practices. Coulthard (1975) observes that speakers don't just stop speaking as conversations virtually always end with a closing pair, composed of good bye, goodnight and so on.

Finally, the analysis has illustrated that the operation of the organised set of practices (machinery) on the various structural units of a conversation makes it easy for us to understand the abstract organisations operating in "talk" independently of the real persons engaged in talking. It is also important to note that the set of organised practices (machinery) operational in talk do operate in contexts of situations. In fact, anything that happens in a conversation happens within some particular, contexts or situation .Sacks, Schegloff, and Jefferson (1974) state, "whatever happens in conversation happens at particular time, in some particular places, with some particular group of persons, after some particular thing has taken place.

\section{Conclusion}

In this study, it has been demonstrated that natural conversation has its distinctive features different from written language and institutional discourse in term of linguistic and discourse features. Interactants generate order within and through talk-in-interaction and conversation analysis serves to interrogate, capture and demonstrate the machinery at work in talk as well as the complexity of the interplay.

In simple terms, the study deconstructs the dynamic and interactive nature of interaction in terms of how people's attention is attracted in opening conversation, how to initiate and manage suitable topics according to the circumstances of the contexts and the relationship between the actors; how to express co-operation and politeness. In specific terms, it has been demonstrated that actors in talk, in rendering potentially face threatening speech-acts such as requests, reprimand e .t .c, do that by using mitigating or softening devices. Strategic devices such as hedges, vague expressions and modality are often used to avoid going straight to the point, speaking directly or again to mitigate the force of what is said.

Finally conversations are collaboratively closed through a number of interactive strategies ranging from the use of announcement closure to make excuse, expansion sequences, pre-closing and terminal exchanges all of which point to the fact that to finish a conversation is often much more involved than simple exchanges of farewell .

\section{References}

Bachman, L. F. (1990). Fundamental considerations. In language testing. Oxford: Oxford University Press.

Bardovi- Harlig, K. B. A. S et al. (1991). Developing pragmatic awareness: closing the conversation; ELT Journal, 45, (1), 4-15.

Bygate, M. (1987). Speaking. Oxford: Oxford University Press.

Canale, M. (1983). From Communicative competence to communicative pedagogy. In J .C. Richards \& R. W Schmidt (Eds). (1983) Language and communication. 2-27. Harlow : Longman.

Cook, G. (1989). Discourse. Oxford University Press.

Coulthard, R. M. (1985). An Introduction to Discourse Analysis. Harlow: Longman.

Crystal, D. and D. Davy. (1975). Advanced conversational English. Harlow: Longman.

Dornyei, Z. \& Thurrel, S. (1994). Teaching conversational skill intensively; course content rationale . ELT Journal, $48(1), 40-49$.

Garfinkel, H. (1967). Studies in Ethnomethodology. New York: Prentice House.

Goffman, E. (1976). Replies and responses. In Language in society, 5(3), 257 -313.

Grice, H. P. (1975). Logic in conversation. In P. Cole \& J. L. Morgan . (Eds.) (1975). Syntax and semantics, 41-58. New York: Academic Press.

Levinson, S. C (1983). Pragmatics .Cambridge: Cambridge University Press.

Liddicoat, A. J. (2007). An introduction to Conversation Analysis. London: continuum.

McCarthy, M. (1991). Discourse Analysis for language teachers. Cambridge: C. U. P.

Richards, J. C. Conversationally speaking: approach to the teaching of conversation. In J. C .Richards The Language teaching matrix.67-86 Cambridge: Cambridge University Press.

Richards. J. C \& M. Sukwiwat. (1983). Language Transfer and Conversational Competence. Applied Linguistics, 4(2), 113-125.

Richards J. C \&Schmidt, R. W. (1983). Conversation Analysis. In J. C Richards \& R. W. Schmidt (Eds). Language and Communication. 4. 177- 154. Harlow: Longman.

Sacks, H. (1973). On some puns with some intimations. Report of the Twenty- Third Annual Round - table Meeting on Linguistics and Language studies. Ed. R. W. Shuy. DC : Georgetown University Press. 44-135. 
Schegloff, E. A. ,Jefferson, G. , \& Sacks, H. (1977). The preference for self- correction in the organization of repair in conversation. Language, 5(3). 361-381.

Schegloff E. A, \& Sacks, H. (197). Opening up closings. Semiotics, 8(3), 289-327.

Silverman, D. (1998). Harvey Sacks : Social science and Conversation analysis. Cambridge: Polity.

Wardhaugh, R. (1985). How conversation works. Oxford: Blackwell.

\section{Appendix}

Setting: At a compound

Participants: Two women who are neighbours living in the same compound. They were later joined by a passer- by.

Transcription Notation: (From Psathas, (1995).

A. Simultaneous utterances: Where two people began to speak at the same time- [

B. Overlapping utterances: Where a speaker starts to talk while the second speaker is still talking- [

C. Contiguous utterances: Where there is no gap between one person's talk finishing and another person's talk starting $=$

D. Intervals within and between utterances: where there is no talk - (0.5), (1.2), etc.

E. Very brief Pauses- (.)

1. Mama Udoka: What is this country turning into eh? =

2. $\quad$ Mama Nkechi: What is it mama Udoka? (0.5)

3. Mama Udoka: How can you be asking that kind of question, mama Nkechi ?

4. Are you from the moon?

5. Are you the only one who does not know what is happening in the northern part of this country?

6. Mama Nkechi: Oh! (0.15) is it the bombings and killings of innocent citizens of the country by the Boko Haram? $=$

7. Mama Udoka: Yes now! This thing is getting out of hand.

8. Do you know the latest?

9. We heard that the bombing which took place in Madala in Niger state on Christmas day killed the only surviving son of late Mazi Nnachi. $=$

10. Mama Nkechi: Don't say that again.

11. Mama Udoka: You mean you've not heard? Huh! The issue now is not that the boy is dead but to break this tragic news to the sick mother.

12. Mama Nkechi: so that woman is sick (.)

13. Why wouldn't she be sick after what she did to herself on the day of her husband's burial.

14. Ewooh! (.) And now her only son who just went back to his base is dead.

15. Chei! (.) Are you sure someone is not behind [all this?

16. Mama Udoka: [How can you say someone sent Boko Haram to kill him.

17. He was not the only one who died in the bomb blast.

18. Passer by: Sorry to interrupt your conversation.

19. Boko Haram is the latest news.

20. I am just coming from that compound where I went to console my colleague whose son was involved in the shooting that took place in Adamawa state by Book Haram.

21. Do you know that this man that was shot just wedded and the wife is even pregnant of their first baby.

22. Mama Udoka : Mama Nkechi, did you hear that?

23. Chineke Onye Ebere!

24. Mama Nkechi: Ewoo! (0.5). What did you just say?

25. Passer-by: If you listen carefully, you're hear the crying of people.

26. In fact people are there now.

27. You'll not even see the leg to come out from the place if you go.

28. I just managed to come out now to rush to my place of work to sign my name in the attendance register and after which I'll come back.

29. Let me run along, bye.

30. Mama Udoka and mama Nkechi: Bye, bye .

31. Mama Udoka: If not that am already late to work, I would have gone there now, but I will do that as soon as am back from work.

32. Mama Nkechi : I' 11 like to go there when the news is fresh.

33. Am going to see you when I come back.

34. Mama Udoka: Bye, bye! 